\title{
Simultaneous Determination of Atenolol and Nifedipine by Using Spectrophotometric Method with Multivariate Calibration and HPLC Method Implementing "Design of Experiment"
}

Inas Abdallah', ${ }^{1,2 *}$, Ahmed Ibrahim ${ }^{1}$, Noha Ibrahim² $^{2}$, Mohamed Rizk³ and Shereen Tawakkol ${ }^{3}$

${ }^{1}$ Department of Pharmaceutical Sciences, School of Pharmacy, University of Maryland, Baltimore, MD

${ }^{2}$ Department of Pharmaceutical Chemistry, Faculty of Pharmacy, Misr International University, Cairo, Egypt

${ }^{3}$ Department of Analytical Chemistry, Faculty of Pharmacy, Helwan University, Cairo, Egypt

\begin{abstract}
Objectives: The aim of the present work is to develop rapid and simple methods for the simultaneous determination of atenolol and nifedipine. Multivariate calibration using preprocessing methods to enhance results in case of presence of any interference in samples and RP-HPLC method for achieving a good separation with accepted system suitability parameters with the use of design of experiment for robustness testing according to Plackett-Burman design.
\end{abstract}

Methods: The spectrophotometric method is based on the measurement of the mixture in the range of 200-400 $\mathrm{nm}$ then applies the multivariate calibration methods for resolution of the binary mixture mainly using partial least squares (PLS) and principal component regression (PCR). The proposed RP-HPLC method utilizes an YMC-pack pro $\mathrm{C}_{18}$ column $(250 \mathrm{~mm} \times 4.6 \mathrm{~mm}, 5 \mu \mathrm{m})$. Optimum chromatographic conditions were attained by application of Design of experiment (DOE). Both spectrophotometric and chromatographic methods were applied on the determination of both drugs in marketed capsules. Also, dissolution testing of these capsules was investigated.

Results: The recovery percentage for nifedipine and atenolol in capsules dosage form were found to be in PLS method $(100.50 \pm 0.850,100.78 \pm 1.07)$. PCR method $(100.60 \pm 0.960,100.72 \pm 1.09)$ and RP-HPLC method (99.77 $\pm 0.560,100.90 \pm 1.23)$; respectively.

Conclusion: The methods were validated according to $\mathrm{ICH}$ guidelines. All the results obtained were found to be within the acceptable limits. The methods were successful to estimate nifedipine and atenolol in bulk powder and pharmaceutical preparation.

Keywords: Nifedipine; Atenolol; Spectrophotometry; Chromatography

\section{Introduction}

Nifedipine [3, 5-dimethyl 2, 6-dimethyl-4-(2-nitrophenyl) - 1, 4-dihydropyridine-3, 5-dicarboxylate] [1]. It is a calcium channel blocker that inhibits the trans membrane influx of calcium ions into vascular smooth muscle and cardiac muscle [2].Atenolol [(RS)-2-[4[2-hydroxy-3-(propan-2-ylamino) propoxy] phenyl] acetamide] [1]. It is a Beta blocker that interferes with the binding to the receptor of epinephrine and other stress hormones, and weakens the effects of these hormones. Beta blockers are particularly used for the management of cardiac arrhythmias, protecting the heart from a second heart attack (myocardial infarction) after a first heart attack (secondary prevention), and hypertension [3]. The combination dosage form of nifedipine and atenolol are available in the market for the treatment of hypertension. Nifedipine and atenolol chemical structures are shown in Figure 1.

According to the international chemometrics society (ICS), chemometrics is defined as the science of relating measurements

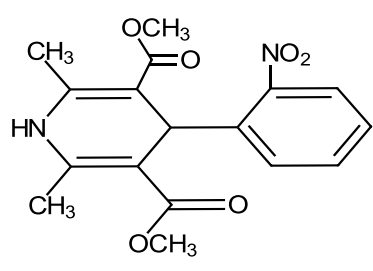

(A)

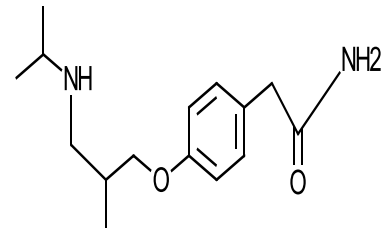

(B)
Figure 1: Chemical structure of: (A) nifedipine and (B) atenolol. made on a chemical system or process to the state of the system via application of mathematical or statistical methods [4]. In this study two chemometric techniques were used, the first technique is the multivariate calibration in spectrophotometry where the absorption spectra of nifedipine and atenolol have a severe overlap that could not be resolved by the simple univariate methods as shown in Figure 2. While the second one is the "Design of experiment" which is used in developing and optimizing a robust chromatographic method.

Quantitative determination using spectrophotometric methods has been greatly improved by the use of multivariate methods. The methods used were principal component regression (PCR) and partial least squares regression (PLS), both are the most popular chemometric tools used for quantitative modeling of the multidimensional spectroscopic data [5]. The method involves calibration; which is the relation between spectra and component concentrations. The validation set and the unknown set can be predicted from a set of reference samples.

*Corresponding author: Inas Abdallah, Department of Pharmaceutical Sciences, University of Maryland School of Pharmacy, 20 N Pine Street, N406, Baltimore, MD 21201, USA, Tel: 410-706-7338; E-mail: iabdallah@rx.umaryland.edu

Received May 03, 2015; Accepted June 30, 2015; Published July 02, 2015

Citation: Abdallah I, Ibrahim A, Ibrahim N, Rizk M, Tawakkol S (2015) Simultaneous Determination of Atenolol and Nifedipine by Using Spectrophotometric Method with Multivariate Calibration and HPLC Method Implementing "Design of Experiment". Pharm Anal Acta 6: 384. doi:10.4172/21532435.1000384

Copyright: $\odot 2015$ Abdallah I, et al. This is an open-access article distributed unde the terms of the Creative Commons Attribution License, which permits unrestricted use, distribution, and reproduction in any medium, provided the original author and source are credited. 
Citation: Abdallah I, Ibrahim A, Ibrahim N, Rizk M, Tawakkol S (2015) Simultaneous Determination of Atenolol and Nifedipine by Using Spectrophotometric Method with Multivariate Calibration and HPLC Method Implementing "Design of Experiment". Pharm Anal Acta 6: 384. doi:10.4172/21532435.1000384

Page 2 of 9

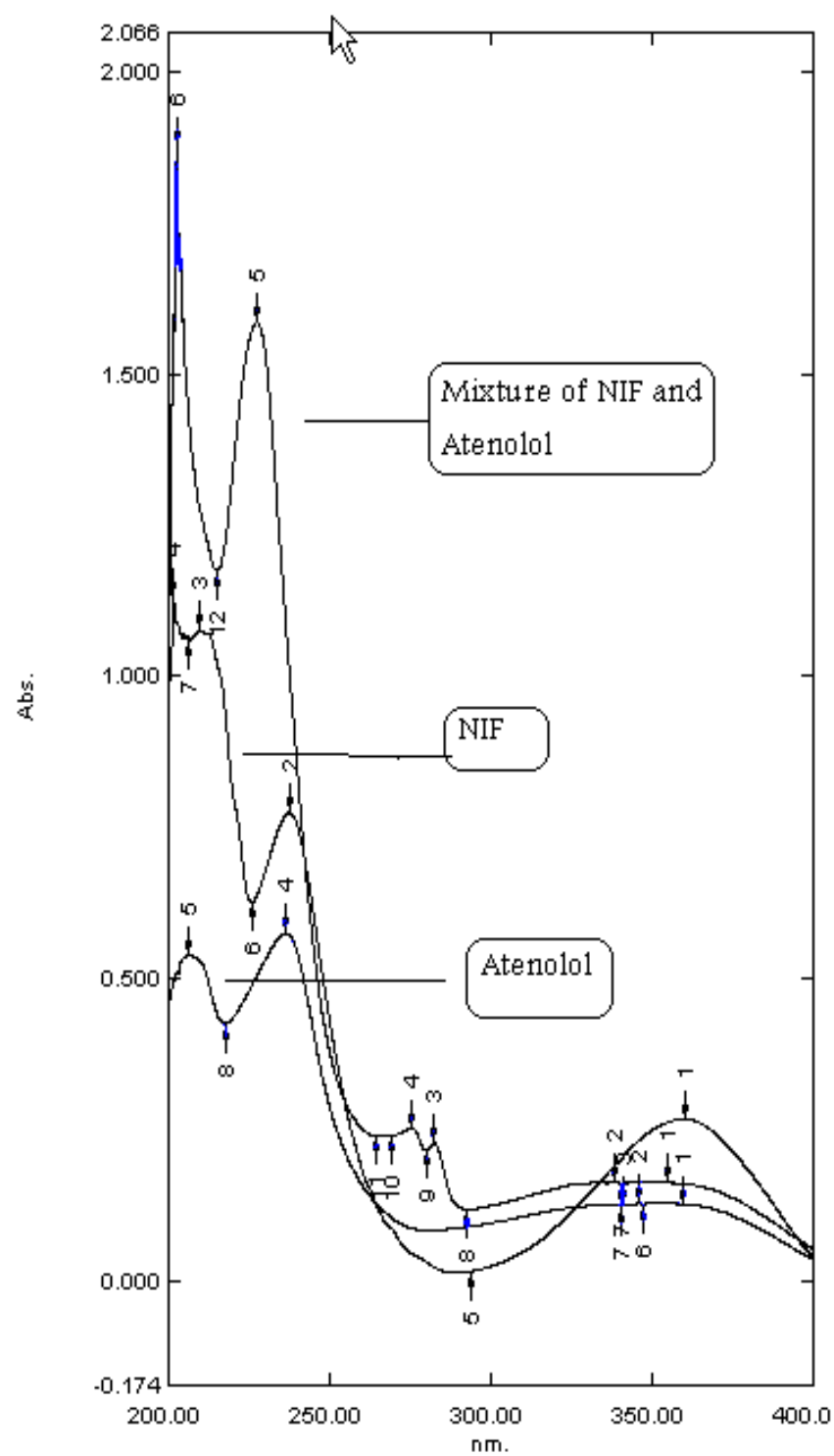

Figure 2: Absorption spectrum of nifedipine and atenolol showing the spectra overlapping.

Design of experiments (DOE) remains a core area of study in chemometrics and it is a well-established statistical method [6,7]. There are levels of design which can be applied: these range from the simplest fractional factorial (which includes experiments to identify which factors are most critical), followed by full factorial (which enables identification of significant interactions between factors), and the more complex surface area design (which facilitates optimization of factors). Accordingly, we applied the simplest design which is two-level PlackettBurman design which is a class from a fractional factorial design to identify the most critical factors to examine the method robustness [8]. The design allows examining $\mathrm{N}-1$ factors in $\mathrm{N}$ experiments, which save time while optimizing experimental conditions. Factorial principles were also used in designing the calibration and validation sets in multivariate calibration.

Several analytical methods have been developed for nifedipine and atenolol quantification in pharmaceuticals. The most recent methods include UV-VIS spectrophotometry [9-14] and HPLC [15-19]. The scientific novelty of the present work is that the methods used are simple, rapid, selective, and less expensive and less time consuming compared with the other published methods. So, the aim of this work was to develop simple, sensitive and validated chemometric and chromatographic methods for the determination of both nifedipine and atenolol in powdered forms and in pharmaceutical formulation. The applied methods are partial least squares (PLS) and principal component regression (PCR) as chemometric methods and reversed phase chromatographic method with the application of design of experiments that lead to fast development and optimization of the experimental conditions.

\section{Materials and Methods}

\section{Chemicals and reagents}

Nifedipine and Atenolol were supplied by E.I.P.I.Co. (Egyptian International Pharmaceutical Industries Company). Methanol was supplied from (Sigma-Aldrich, Germany) (HPLC grade). Sodium dihydrogen phosphate and orthophosphoric acid were supplied from (Adwic, Egypt). Tenolate S.R' capsules (B.N. 12746) were manufactured by Tiba pharmaceutical industries. It is labeled to contain $20 \mathrm{mg}$ of nifedipine and $50 \mathrm{mg}$ of atenolol and was obtained from the local market.

\section{Instruments}

A double beam UV-Visible spectrophotometer (SHIMADZU, Kyoto, Japan) model UV-1601 PC. The bundled software was UV-PC personal spectroscopy software version 2.10 (Shimadzu). The spectral bandwidth was $0.1 \mathrm{~nm}$ and wavelength-scanning speed $1800 \mathrm{~nm} / \mathrm{min}$. The absorption spectra of the standard were recorded in $1 \mathrm{~cm}$ quartz cells over the range of 200-400 $\mathrm{nm}$ at room temperature. Data handling was done using PLS toolbox, Solo version 7.0.3.

An HPLC system equipped with an isocratic pump UV detector Agilent 1100. Chromatographic signals were acquired processed by Agilent LC Chemstation software 1100. YMC-pack pro $C_{18}$ ODSA (250 $\mathrm{mm} \times 4.6 \mathrm{~mm}, 5 \mu \mathrm{m}$ ) column was used for separation.

\section{Preparation of solutions}

Stock solutions of 0.1 and $0.25 \mathrm{mg} / \mathrm{mL}$ of nifedipine and atenolol; respectively were prepared in methanol. Working solutions were prepared by diluting the stock solution with methanol as appropriate. The stock solutions were found to be stable for one week if kept in the refrigerator and protected from light.

\section{Standard solution for multivariate calibration}

A multilevel multifactor design was used for the construction of the calibration and validation set. A training set of 25 synthetic mixtures with different concentration ratios of nifedipine and atenolol was prepared by mixing different aliquots of working standard solutions in $10 \mathrm{~mL}$ volumetric flasks then the volumes were completed with methanol. The resulting concentrations of nifedipine and atenolol were in the ranges $5-15 \mu \mathrm{g} / \mathrm{mL}$ and $20-30 \mu \mathrm{g} / \mathrm{mL}$; respectively. One third of the samples (Eight samples) were randomly chosen and used for external validation (validation set) and the rest of the samples were used for construction of the regression model (calibration set). Table 1 shows the concentrations of the prepared mixtures.

\section{Chromatographic conditions for HPLC method}

Different chromatographic conditions were tested by changing different factors (acetonitrile ratio, $\mathrm{pH}$ of phosphate buffer, flow rate 
Citation: Abdallah I, Ibrahim A, Ibrahim N, Rizk M, Tawakkol S (2015) Simultaneous Determination of Atenolol and Nifedipine by Using Spectrophotometric Method with Multivariate Calibration and HPLC Method Implementing "Design of Experiment". Pharm Anal Acta 6: 384. doi:10.4172/21532435.1000384

Page 3 of 9

\begin{tabular}{|c|c|c|c|c|}
\hline \multirow[b]{2}{*}{ Sample No. } & \multicolumn{2}{|c|}{ Calibration set } & \multicolumn{2}{|c|}{ Validation set } \\
\hline & $\begin{array}{l}\text { Nifedipine concentration } \\
(\mu \mathrm{g} / \mathrm{mL})\end{array}$ & $\begin{array}{c}\text { Atenolol concentration } \\
(\mu \mathrm{g} / \mathrm{mL})\end{array}$ & $\begin{array}{l}\text { Nifedipine concentration } \\
(\mu \mathrm{g} / \mathrm{mL})\end{array}$ & $\begin{array}{l}\text { Atenolol concentration } \\
(\mu \mathrm{g} / \mathrm{mL})\end{array}$ \\
\hline 1 & 5 & 25 & 10 & 25 \\
\hline 2 & 5 & 20 & 7.5 & 22.5 \\
\hline 3 & 15 & 20 & 12.5 & 30 \\
\hline 4 & 7.5 & 30 & 10 & 27.5 \\
\hline 5 & 15 & 22.5 & 15 & 25 \\
\hline 6 & 10 & 30 & 12.5 & 20 \\
\hline 7 & 7.5 & 25 & 10 & 20 \\
\hline 8 & 12.5 & 22.5 & 12.5 & 27.5 \\
\hline 9 & 15 & 27.5 & - & - \\
\hline 10 & 15 & 30 & - & - \\
\hline 11 & 5 & 30 & - & - \\
\hline 12 & 5 & 27.5 & - & - \\
\hline 13 & 12.5 & 25 & - & - \\
\hline 14 & 7.5 & 27.5 & - & - \\
\hline 15 & 5 & 22.5 & - & - \\
\hline 16 & 7.5 & 20 & - & - \\
\hline 17 & 10 & 22.5 & - & - \\
\hline
\end{tabular}

Table 1: The five level two factor experimental design of the calibration and validation set mixtures.

\begin{tabular}{|c|c|c|c|c|}
\hline Factors & DOE I & DOE II & DOE III & DOE IV \\
\hline $\mathrm{pH}$ & $-1=3,0=4,+1=5$ & $-1=4,0=5,+1=6$ & $-1=3.9,0=4,+1=4.1$ & $-1=3.9,0=4,+1=4.1$ \\
\hline Flow rate & $-\mathbf{1}=0.8, \mathbf{0}=1,+\mathbf{1}=1.2$ & $-1=1,0=1.2,+1=1.4$ & $-\mathbf{1}=1.2, \mathbf{0}=1.4,+\mathbf{1}=1.6$ & $\mathbf{- 1}=1.1, \mathbf{0}=1.2,+\mathbf{1}=1.3$ \\
\hline Acetonitrile & $-1=40,0=50,+1=60$ & $-1=55,0=60,+1=65$ & $-1=62.5,0=65,+1=67.5$ & $-1=60.5,0=62.5,+1=64.5$ \\
\hline Wavelength & $-1=220,0=230,+1=240$ & $-1=210,0=220,+1=230$ & $-1=229,0=230,+1=231$ & $-1=229,0=230,+1=231$ \\
\hline
\end{tabular}

Table 2: Experimental design (DOE I, II, III and IV) to develop and optimize the chromatographic conditions for nifedipine and atenolol mixture.

and wavelength of detection) using experimental design till reaching optimum chromatographic conditions for good resolution of both drugs as shown in Table 2. The optimum conditions that was achieved: (acetonitrile: $0.02 \mathrm{M}$ phosphate buffer, $\mathrm{pH}=4.0)(62.5: 37.5, \mathrm{v} / \mathrm{v})$. The phosphate buffer was prepared by adding $10 \mathrm{~mL}$ of triethylamine to the prepared buffer $(0.01 \mathrm{M})$. The $\mathrm{pH}$ adjusted using orthophosphoric acid. The mobile phase was prepared, filtered through $0.45 \mu \mathrm{m}$ membrane filter and degassed before use, at flow rate $1.2 \mathrm{~mL} / \mathrm{min}$ and detection wavelength at $230 \mathrm{~nm}$. Validation of the chromatographic method was done according to ICH guidelines [20].

\section{Linearity}

Different aliquots (0.5-3.5 mL) of nifedipine and (3.5-6.5 mL) of atenolol standard solutions $(100 \mu \mathrm{g} / \mathrm{mL})$ were transferred into two series of $10 \mathrm{~mL}$ volumetric flasks; each was diluted with the mobile phase to reach the required concentration. Solutions were injected in triplicate with $20 \mu \mathrm{L}$ injection volume.

\section{Accuracy}

The accuracy of the method was demonstrated by analyzing different concentrations covering the points in the calibration range $(10,15,20,25,30 \mu \mathrm{g} / \mathrm{mL})$ for nifedipine and $(40,45,50,55,60 \mu \mathrm{g} / \mathrm{mL})$ for atenolol. All concentrations were injected in triplicate.

\section{Precision}

Repeatability: Repeatability was demonstrated by assaying three freshly prepared solutions in triplicates on the same day at concentrations $(18,20,22 \mu \mathrm{g} / \mathrm{mL})$ for nifedipine and $(45,50,55 \mu \mathrm{g} /$ $\mathrm{mL}$ ) for atenolol.

Intermediate precision: Intermediate precision was studied by assaying the previously mentioned concentration under repeatability within different days.

\section{Sensitivity}

Limit of detection (LOD): The detection limit of an individual analytical procedure is the lowest amount of analyte in a sample which can be detected but not necessarily quantitated as an exact value. The Limit of detection was calculated according to the following equation: $\mathrm{LOD}=3.3 \sigma / \mathrm{S}$ where, $\sigma=$ the standard deviation of the response and $\mathrm{S}$ $=$ the slope of the calibration curve.

Limit of quantitation (LOQ): The quantitation limit of an individual analytical procedure is the lowest amount of analyte in a sample which can be quantitatively determined with suitable precision and accuracy. The quantitation limit is a parameter of quantitative assays for low levels of compounds in sample matrices, and is used particularly for the determination of impurities and/or degradation products.

The limit of quantitation was calculated according to the following equation: $\mathrm{LOQ}=10 \sigma / \mathrm{S}$ where $\sigma=$ the standard deviation of the response $\mathrm{S}=$ the slope of the calibration curve.

\section{Application to Pharmaceutical Preparation}

The method was applied on Tenolate S.R capsules (labeled to contain $20 \mathrm{mg}$ nifedipine and $50 \mathrm{mg}$ atenolol per capsule). Twenty capsules were emptied, weighed and finely grinded, an amount of the powder equivalent to $10 \mathrm{mg}$ nifedipine and $25 \mathrm{mg}$ of atenolol were placed in a $100 \mathrm{~mL}$ volumetric flask and dissolved in $50 \mathrm{~mL}$ of methanol and the solution was sonicated for 45 minutes. The volume was completed with the same solvent and the solution was then filtered through a filter paper to a concentration of 100 and $250 \mu \mathrm{g} / \mathrm{mL}$ for nifedipine and atenolol; respectively. An aliquot of $(2.5 \mathrm{~mL})$ was diluted with methanol 
Citation: Abdallah I, Ibrahim A, Ibrahim N, Rizk M, Tawakkol S (2015) Simultaneous Determination of Atenolol and Nifedipine by Using Spectrophotometric Method with Multivariate Calibration and HPLC Method Implementing "Design of Experiment". Pharm Anal Acta 6: 384. doi:10.4172/21532435.1000384

in a $10 \mathrm{~mL}$ volumetric flask to reach a final concentration of 10 and 25 $\mu \mathrm{g} / \mathrm{mL}$ for both nifedipine and atenolol; respectively.

\section{Dissolution and release studies}

Dissolution study was done on Tenolate S.R. capsule $(20 \mathrm{mg}$ nifedipine/50 $\mathrm{mg}$ atenolol). The release studies of a delayed drug delivery system (DDS) as Tenolate ${ }^{\circ}$ S.R capsules which releases nifedipine after a programmable period of time, which is intended for the therapy of diseases that depend on circadian rhythms. While, atenolol is usually given as a single oral dose effective antihypertensive agent providing 24 - hour reduction of blood pressure [21].

\section{USP Dissolution testing of Tenolate S.R. capsules}

The release studies of nifedipine and atenolol were determined using USP dissolution testing apparatus I (Basket apparatus) [22] where it is preferable for floating dosage forms as capsules. The dissolution testing was performed using $900 \mathrm{~mL}$ phosphate buffer of $\mathrm{pH} 6.8$ at $37 \pm$ $0.5^{\circ} \mathrm{C}$ and speed $100 \mathrm{rpm}$. An aliquot of $9 \mathrm{~mL}$ was withdrawn at regular interval of time $(10,20,30,60,90,120,180,210,240,300$ and $360 \mathrm{~min}$.) and replaced with fresh medium to maintain sink conditions. These aliquots were filtered and diluted to a $10 \mathrm{~mL}$ volumetric flask with the mobile phase to give a final concentration of $(50 \mu \mathrm{g} / \mathrm{mL}$ atenolol and 20 $\mu \mathrm{g} / \mathrm{mL}$ nifedipine) then analyzed using the developed HPLC method. For calibration purposes, the linearity of both drugs were used as a secondary standard of known content and quantity of nifedipine and atenolol dissolved in the medium were calculated.

\section{Dissolution of Tenolate ${ }^{\circledR}$ S.R. capsules using a surfactant}

The release studies of nifedipine and atenolol were determined using USP dissolution testing apparatus I (Basket apparatus). The dissolution testing was performed using $900 \mathrm{~mL}$ phosphate buffer of $\mathrm{pH} 6.8$ with the addition of $1 \%$ sodium lauryl sulfate (SLS) at $37 \pm 0.5^{\circ} \mathrm{C}$ and speed $100 \mathrm{rpm}$. An aliquot of $9 \mathrm{~mL}$ was withdrawn at regular interval of time $(5,10,20,30,45,60,75,90,120,180,240,270,300$ and $330 \mathrm{~min}$.$) and$ replaced with fresh medium to maintain sink conditions. These aliquots were filtered and diluted to a $10 \mathrm{~mL}$ volumetric flask with the mobile phase to give a final concentration of $(50 \mu \mathrm{g} / \mathrm{mL}$ atenolol and $20 \mu \mathrm{g} / \mathrm{mL}$ nifedipine) and analyzed using the developed HPLC method.

\section{Results and Discussion}

\section{Multivariate calibration}

In PCR and PLS methods, data were mean centered as a preprocessing step and leave one out was applied as a cross validation method [23]. To select the optimum number of PCs and LVs, F statistics was used in which the root mean square error of cross validation (RMSECV) values were compared and the selected model was that with the smallest number of factors such that RMSECV for that model was not significantly greater than RMSECV from the model with an additional factor (LV) [24]. If we decided to retain more factors than we should, we would be retaining some factors that can only add more noise to our data. On the other hand, if we don't keep enough factors, we will be discarding potentially meaningful information that could be necessary for a successful calibration. It was found that the optimum number of PCs and LVs were two as shown in Figure 3.

To validate the suggested models, several diagnostic tools were used for predicting a mixture containing different ratios of both drugs. The predicted validation set were shown with their recoveries, standard deviation and relative standard deviations values using PLS and PCR models are summarized in Table 3.
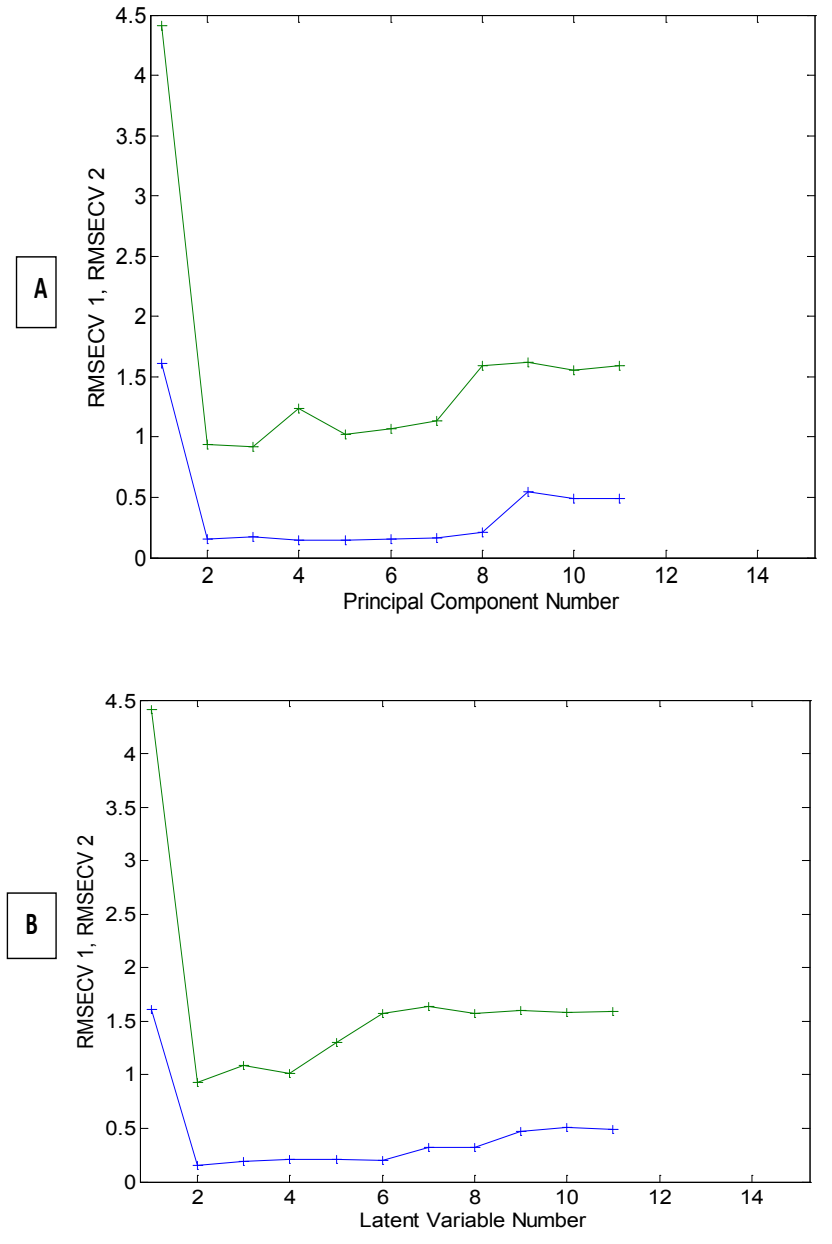

Figure 3: Plot of RMSECV versus (a) the number of principal components using PCR model and (b) the number of Latent variable using PLS model.

\begin{tabular}{|c|c|c|c|c|}
\hline \multirow{2}{*}{ Sample No. } & \multicolumn{2}{|c|}{$\begin{array}{c}\text { PCR } \\
\text { (\%Recovery) }\end{array}$} & \multicolumn{2}{c|}{$\begin{array}{c}\text { PLS } \\
\text { (\%Recovery) }\end{array}$} \\
\cline { 2 - 5 } & Nifedipine & Atenolol & Nifedipine & Atenolol \\
\hline $\mathbf{1}$ & 99.90 & 100.80 & 99.90 & 100.72 \\
\hline $\mathbf{2}$ & 101.33 & 99.77 & 101.33 & 99.77 \\
\hline $\mathbf{3}$ & 99.28 & 101.46 & 99.44 & 101.36 \\
\hline $\mathbf{4}$ & 98.50 & 101.89 & 98.50 & 101.89 \\
\hline $\mathbf{5}$ & 101.66 & 100.24 & 101.60 & 100.24 \\
\hline $\mathbf{6}$ & 100.00 & 102.75 & 100.08 & 102.70 \\
\hline $\mathbf{7}$ & 97.80 & 99.50 & 97.80 & 99.50 \\
\hline $\mathbf{8}$ & 100.72 & 101.78 & 100.72 & 101.78 \\
\hline Mean & $\mathbf{9 9 . 8 9}$ & $\mathbf{1 0 1 . 0 2}$ & $\mathbf{9 9 . 9 2}$ & $\mathbf{1 0 0 . 9 9}$ \\
\hline \% RSD & $\mathbf{1 . 3 4}$ & $\mathbf{1 . 3 5}$ & $\mathbf{1 . 3 2}$ & $\mathbf{1 . 1 0}$ \\
\hline
\end{tabular}

Table 3: Percent recoveries of nifedipine and atenolol in the validation set by PCR and PLS regression models.

In order to assess the predictive ability of the developed models, each model was applied for determination of nifedipine and atenolol in the validation set. The expected concentration versus the predicted concentration for each compound is shown in Figures 4 and 5. Root mean squared error of cross-validation (RMSECV), of calibration (RMSEC) and prediction (RMSEP), together with the statistical 
Citation: Abdallah I, Ibrahim A, Ibrahim N, Rizk M, Tawakkol S (2015) Simultaneous Determination of Atenolol and Nifedipine by Using Spectrophotometric Method with Multivariate Calibration and HPLC Method Implementing "Design of Experiment". Pharm Anal Acta 6: 384. doi:10.4172/21532435.1000384
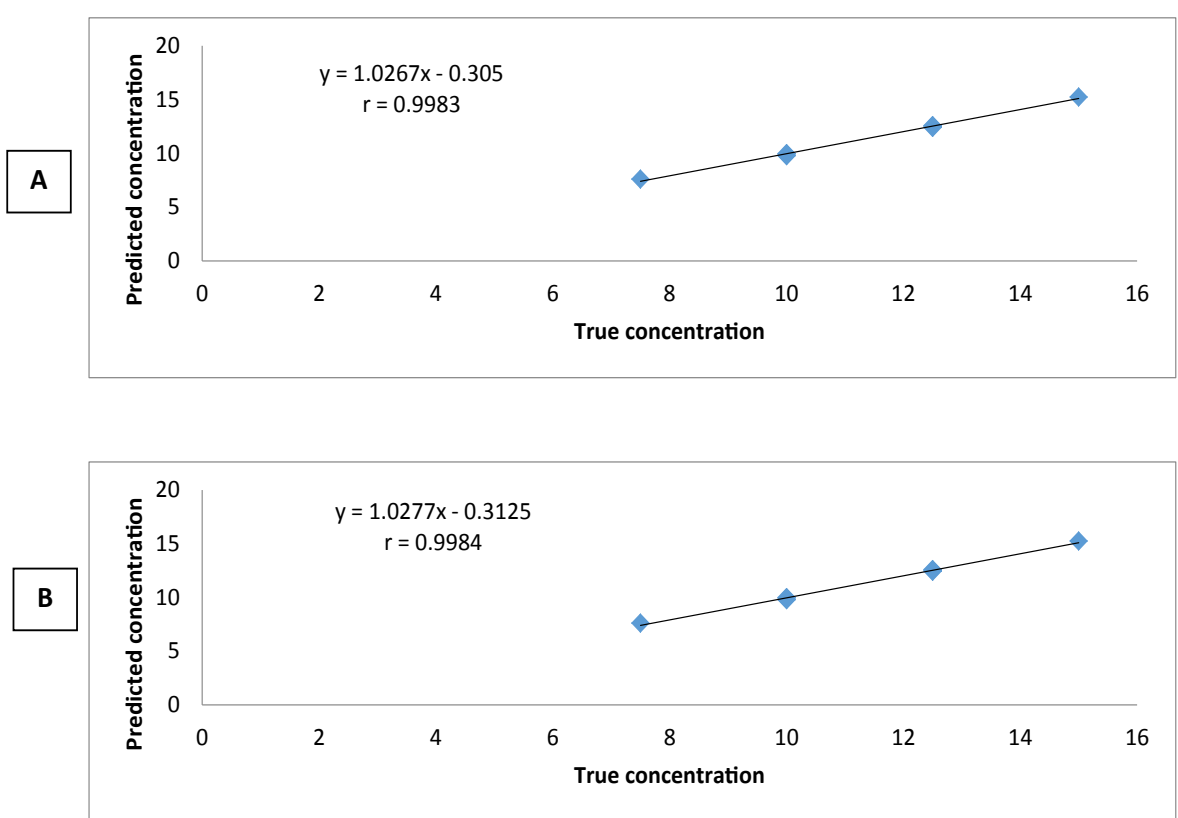

Figure 4: Plot of expected concentrations $(\mu \mathrm{g} / \mathrm{mL})$ versus predicted concentrations $(\mu \mathrm{g} / \mathrm{mL})$ for nifedipine using (a) PCR, (b) PLS models.

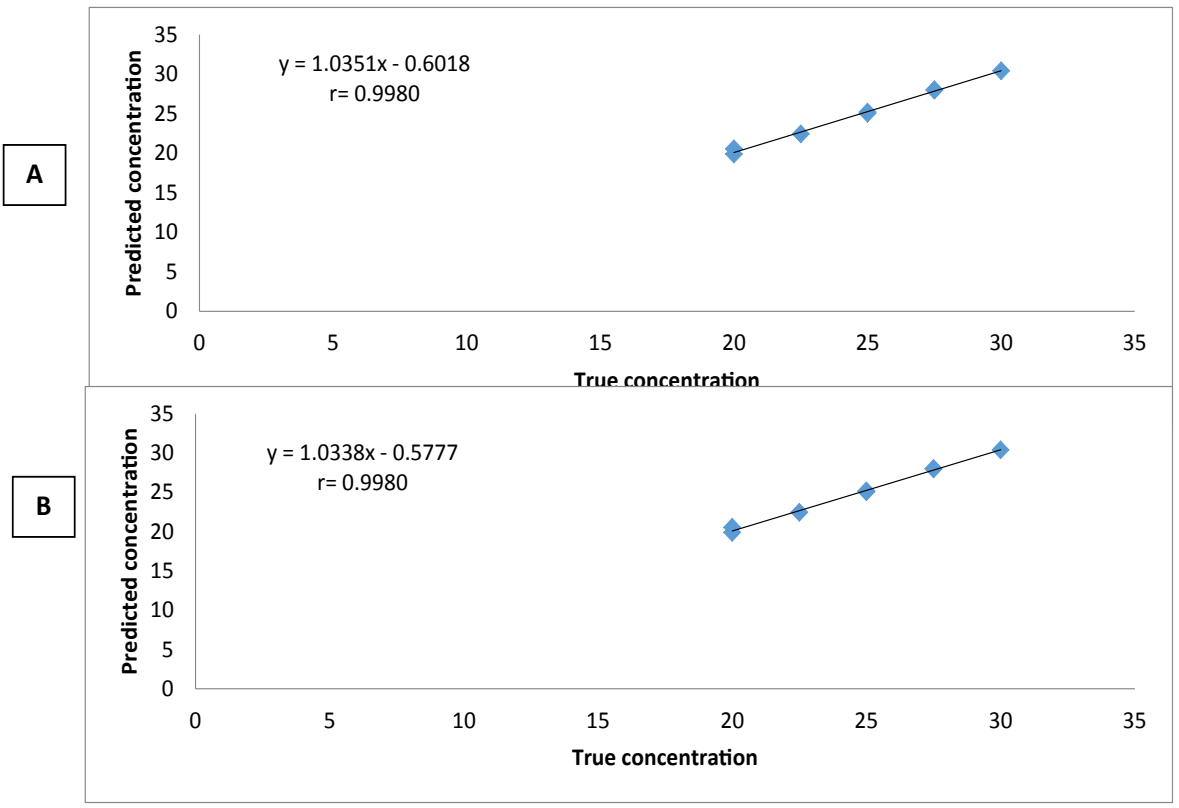

Figure 5: Plot of expected concentrations $(\mu \mathrm{g} / \mathrm{mL})$ versus predicted concentrations $(\mu \mathrm{g} / \mathrm{mL})$ for atenolol using (a) PCR, (b) PLS models.

parameters of the linear relationship between the predicted and the expected concentration of nifedipine and atenolol in the validation set are presented in Table 4.

\section{Chromatographic method}

An HPLC method was developed and validated for quantitative determination of nifedipine and atenolol in bulk powder and in pharmaceutical preparation. The chromatograms of both drugs are shown in Figure 6.

The method was developed using the concept of DOE after the application of four design of experiments (DOE) by testing 4 factors $(\mathrm{pH}$, Acetonitrile ratio, flow rate and wavelength of detection). NonSignificant experimental factors were attained and hence a robust method.

The method was validated for Linearity, Precision (repeatability and intermediate precision), LOD (Limit of detection), LOQ (Limit of quantitation) and accuracy according to the ICH guidelines [20]. The robustness study was carried out statistically by the design of experiments using MODDE 9.0 (trial version). 
Citation: Abdallah I, Ibrahim A, Ibrahim N, Rizk M, Tawakkol S (2015) Simultaneous Determination of Atenolol and Nifedipine by Using Spectrophotometric Method with Multivariate Calibration and HPLC Method Implementing "Design of Experiment". Pharm Anal Acta 6: 384. doi:10.4172/21532435.1000384

Page 6 of 9

\section{Linearity}

The chromatographic method was found to be linear in the range of $(5-35 \mu \mathrm{g} / \mathrm{mL})$ for nifedipine and $(35-65 \mu \mathrm{g} / \mathrm{mL})$ for atenolol. Regression equations were as follows:

$\mathrm{Y}=62.83 \mathrm{X}+24.06(\mathrm{r}=0.9999)($ Nifedipine$)$ and $\mathrm{Y}=35.21 \mathrm{X}-31$ $(\mathrm{r}=0.9998)($ Atenolol $)$

\section{Accuracy}

The average percentage recovery at each concentration level was determined, the mean percentage recovery and RSD values were calculated as shown in Table 5.

\section{Precision}

Repeatability: Relative standard deviation values were 1.58 and 1.32 for nifedipine and atenolol; respectively.

Intermediate precision: Relative standard deviation values were 0.549 and 0.706 for nifedipine and atenolol; respectively.

\section{Sensitivity}

Limit of detection (LOD): The Limit of detection values were found to be 1.08 and $2.18 \mu \mathrm{g} / \mathrm{mL}$ for nifedipine and atenolol; respectively.

Limit of quantitation (LOQ): The limit of quantitation values

\begin{tabular}{|c|c|c|c|c|}
\hline \multirow[t]{2}{*}{ Parameters } & \multicolumn{2}{|c|}{$\operatorname{PCR}(2)^{a}$} & \multicolumn{2}{|c|}{$\operatorname{PLS}(2)^{b}$} \\
\hline & Nifedipine & Atenolol & Nifedipine & Atenolol \\
\hline \multicolumn{5}{|l|}{ Root mean square errors } \\
\hline RMSEC & 0.13 & 0.71 & 0.13 & 0.70 \\
\hline RMSECV & 0.15 & 0.93 & 0.15 & 0.92 \\
\hline RMSEP & 0.13 & 0.36 & 0.13 & 0.36 \\
\hline \multicolumn{5}{|l|}{ Regression parameters } \\
\hline Slope & 1.026 & 1.035 & 1.027 & 1.033 \\
\hline Intercept & -0.305 & -0.601 & -0.312 & -0.577 \\
\hline Correlation Coefficient ( $r$ ) & 0.9983 & 0.9980 & 0.9984 & 0.9980 \\
\hline
\end{tabular}

aThe number of PCR factors (PCs) are represented in parentheses.

${ }^{\mathrm{b}}$ The number of PLS factors (LVs) are represented in parentheses.

Table 4: Root mean squared error of cross-validation (RMSECV), of calibration (RMSEC) and prediction (RMSEP), together with linear regression parameters of the linear relationship between the expected and the predicted values of nifedipine and atenolol in the validation set by the proposed chemometric methods

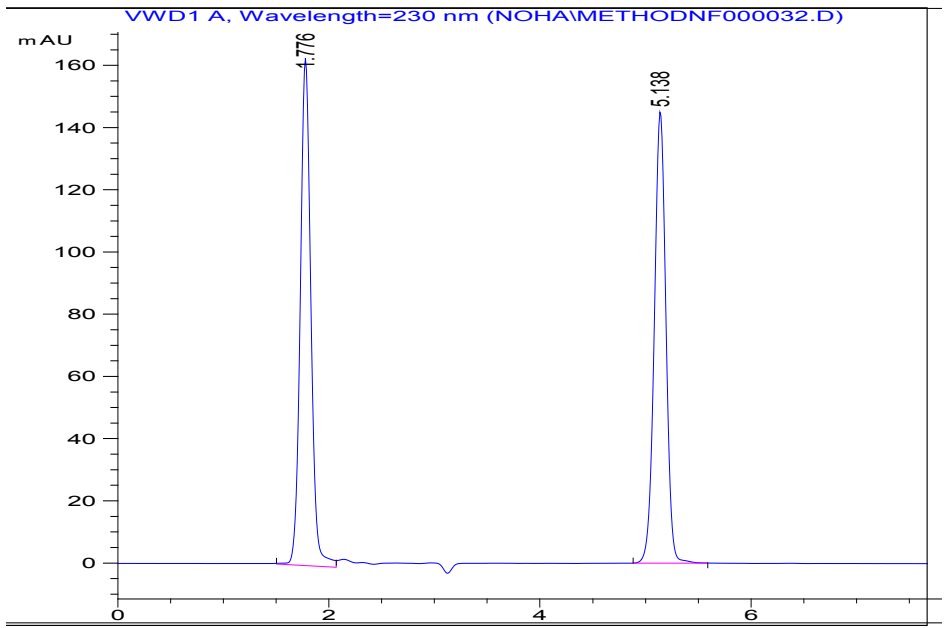

Figure 6: HPLC chromatogram of a resolved mixture of atenolol $(50 \mu \mathrm{g} / \mathrm{mL})\left(\mathrm{t}_{\mathrm{R}}=1.77\right)$ and nifedipine $(20 \mu \mathrm{g} / \mathrm{mL})\left(\mathrm{t}_{\mathrm{R}}=5.13\right)$.

\begin{tabular}{|c|c|c|c|c|c|c|}
\hline \multirow[t]{2}{*}{$\begin{array}{c}\text { Sample } \\
\text { No. }\end{array}$} & \multicolumn{2}{|c|}{$\begin{array}{l}\text { Taken } \\
(\mu \mathrm{g} / \mathrm{mL})\end{array}$} & \multicolumn{2}{|c|}{$\begin{array}{l}\text { Found* } \\
\text { ( } \mu \mathrm{g} / \mathrm{mL})\end{array}$} & \multicolumn{2}{|c|}{$\%$ Recovery } \\
\hline & Nifedipine & Atenolol & Atenolol & Nifedipine & Atenolol & Nifedipine \\
\hline 1 & 10 & 40 & 9.98 & 39.93 & 99.84 & 99.83 \\
\hline 2 & 15 & 45 & 15.12 & 45.34 & 100.86 & 100.76 \\
\hline 3 & 20 & 50 & 20.07 & 50.08 & 100.37 & 100.17 \\
\hline 4 & 25 & 55 & 24.97 & 54.39 & 99.90 & 98.90 \\
\hline 5 & 30 & 60 & 30.00 & 59.96 & 100.00 & 99.94 \\
\hline Mean \pm SD & & & & & $100.19 \pm 0.380$ & $99.92 \pm 0.662$ \\
\hline$\%$ RSD & & & & & 0.379 & 0.660 \\
\hline
\end{tabular}

*Average of 3 determinations.

Table 5: Accuracy expressed as \% recovery of nifedipine and atenolol in their standard solutions by the proposed HPLC method. 
Citation: Abdallah I, Ibrahim A, Ibrahim N, Rizk M, Tawakkol S (2015) Simultaneous Determination of Atenolol and Nifedipine by Using Spectrophotometric Method with Multivariate Calibration and HPLC Method Implementing "Design of Experiment". Pharm Anal Acta 6: 384. doi:10.4172/21532435.1000384

Page 7 of 9

were found to be 3.29 and $6.62 \mu \mathrm{g} / \mathrm{mL}$ for nifedipine and atenolol; respectively.

The summary of regression and validation parameters for determination of nifedipine and atenolol are shown in Table 6.

Suitability parameters: System suitability parameters [25] were calculated for each chromatographic run for both drugs as shown in Table 7.

Statistically Designed Robustness Experiments: The concept

\begin{tabular}{|c|c|c|c|}
\hline \multicolumn{2}{|c|}{ Parameters } & Nifedipine & Atenolo \\
\hline \multicolumn{2}{|c|}{ Linearity (Range) $(\mu \mathrm{g} / \mathrm{mL})$} & $5-35$ & $35-65$ \\
\hline \multicolumn{2}{|c|}{ Intercept coefficient } & 24.05 & -31 \\
\hline \multicolumn{2}{|c|}{ Slope coefficient } & 62.834 & 35.21 \\
\hline \multicolumn{2}{|c|}{ Correlation coefficient ( $r$ ) } & 0.9999 & 0.9998 \\
\hline \multicolumn{2}{|c|}{$\operatorname{LOD}(\mu \mathrm{g} / \mathrm{mL})$} & 1.08 & 2.18 \\
\hline \multicolumn{2}{|c|}{$\mathrm{LOQ}(\mu \mathrm{g} / \mathrm{mL})$} & 3.29 & 6.62 \\
\hline \multirow{2}{*}{ Precision } & Repeatability & 1.582 & 1.324 \\
\hline & Intermediate precision & 0.549 & 0.706 \\
\hline
\end{tabular}

Table 6: Assay parameters and method validation for the determination of nifedipine and atenolol by the proposed HPLC method. of DOE was used for determining the effect of 4 factors in only 11 experiments. The design of experiment (DOE) used was two - level placket - Burman design, the effect of each factor was computed by MODDE 9.0 trial version with respect to resolution, symmetry and selectivity. All factors were found to be non-significant $(\mathrm{P}<0.05)$ as shown in the coefficient plot as presented in Figure 7.

Application to pharmaceutical preparation: Application of both spectrophotometric and chromatographic methods on pharmaceutical dosage form were demonstrated by preparing six replicate sample solutions of Tenolate SR capsules (20 mg nifedipine/50 mg atenolol) with good recoveries as shown in Table 8 .

USP Dissolution testing of Tenolate S.R. capsules: It was clear from the dissolution profiles of both nifedipine and atenolol that atenolol is immediately released. While, nifedipine is sustainably released after 7 hours as shown in Figure 8. To accelerate the release of the nifedipine, sodium lauryl sulphate (SLS) with a concentration of $1 \%$ was added to the medium with same USP dissolution conditions. As a result, nifedipine released faster till it was completely released after 6 hours while atenolol was not affected as shown in Figure 9.

The results obtained by applying the proposed spectrophotometric

\begin{tabular}{|c|c|c|c|}
\hline Parameters & Nifedipine & Atenolol & Reference value* \\
\hline Resolution (Rs) & - & 18.32 & $\geq 2$ \\
\hline Relative retention time & 1.78 & 4.84 & $>1$ \\
\hline Tailing factor $(\mathrm{t})$ & 0.85 & 1.01 & $0.5-2$ \\
\hline Capacity factor (K') & 1.78 & 1.70 & $>2$ \\
\hline Height equivalent to theoretical plates $(\mathrm{H}=\mathrm{L} / \mathrm{N})$ & 0.006 & 0.0008 & The smaller the value, the more efficient separation \\
\hline Number of theoretical plates $(\mathrm{N})$ & 2234 & 10929 & The higher the value, the more efficient separation \\
\hline
\end{tabular}

${ }^{*}$ FDA regulations [25]

Table 7: System suitability parameters of analysis of nifedipine and atenolol by the proposed HPLC method.
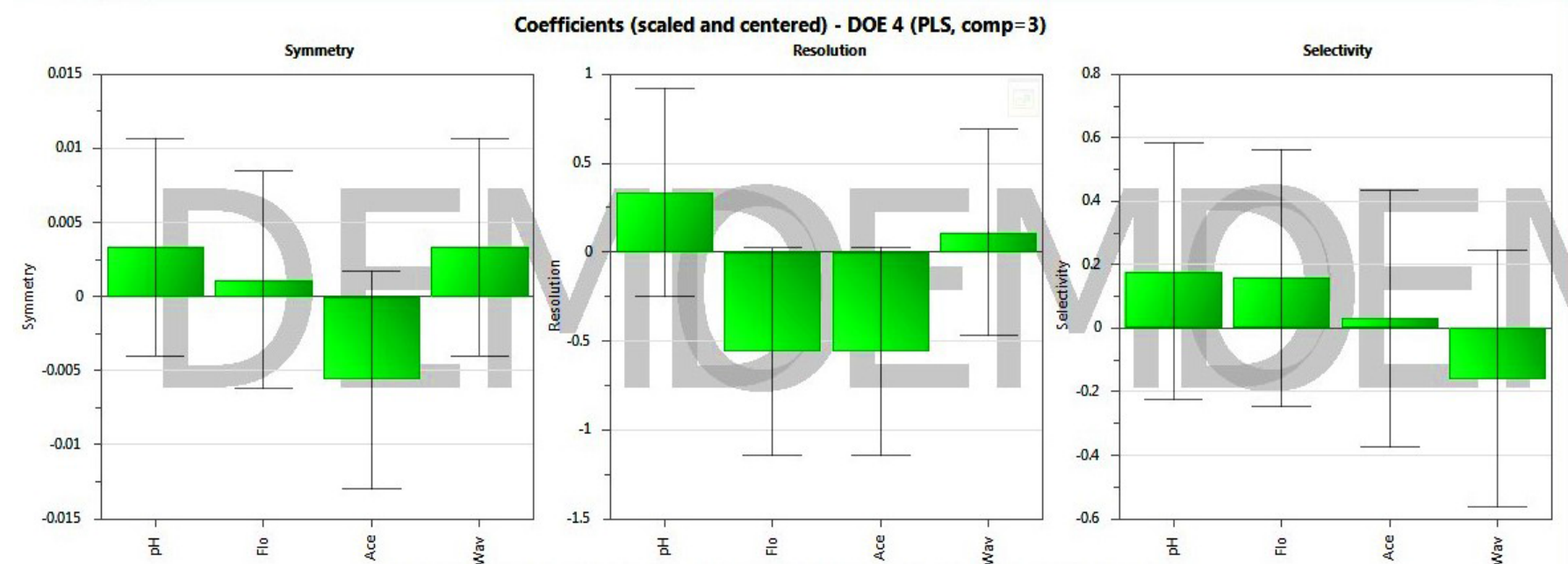

Figure 7: The Coefficient plot of DOE IV (robustness) of nifedipine and atenolol that shows the factors influencing the chromatographic separation of the critical pair.

\begin{tabular}{|l|c|c|}
\hline & Methods & \multicolumn{1}{|c|}{$\begin{array}{c}\text { Atenolol } \\
(\text { Mean } \pm \text { SD) }\end{array}$} \\
\hline Tenolate $₫$ SR Capsules \\
\begin{tabular}{l|l|} 
Claimed to contain $20 \mathrm{mg}$ Nifedipine and $50 \mathrm{mg}$ Atenolol \\
Batch No. 12746
\end{tabular} & PLS & $100.50 \pm 0.85$ \\
\hline
\end{tabular}

*Average of 3 determinations.

Table 8: Application of the proposed methods to Tenolate $\mathrm{SR}^{\circledR}$ capsules (20 mg Nifedipine/50 mg Atenolol). 
Citation: Abdallah I, Ibrahim A, Ibrahim N, Rizk M, Tawakkol S (2015) Simultaneous Determination of Atenolol and Nifedipine by Using Spectrophotometric Method with Multivariate Calibration and HPLC Method Implementing "Design of Experiment". Pharm Anal Acta 6: 384. doi:10.4172/21532435.1000384
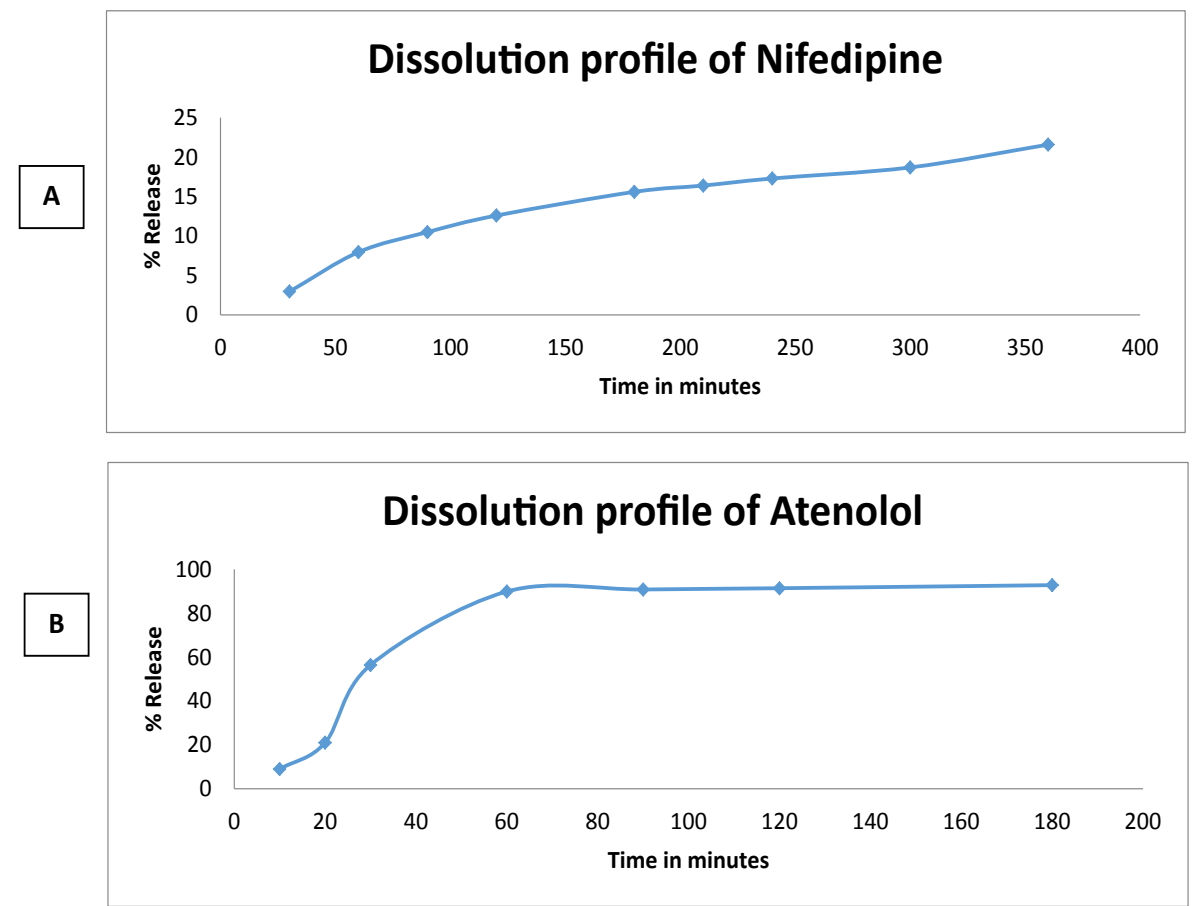

Figure 8: Dissolution of (A) nifedipine and (B) atenolol using USP apparatus method.
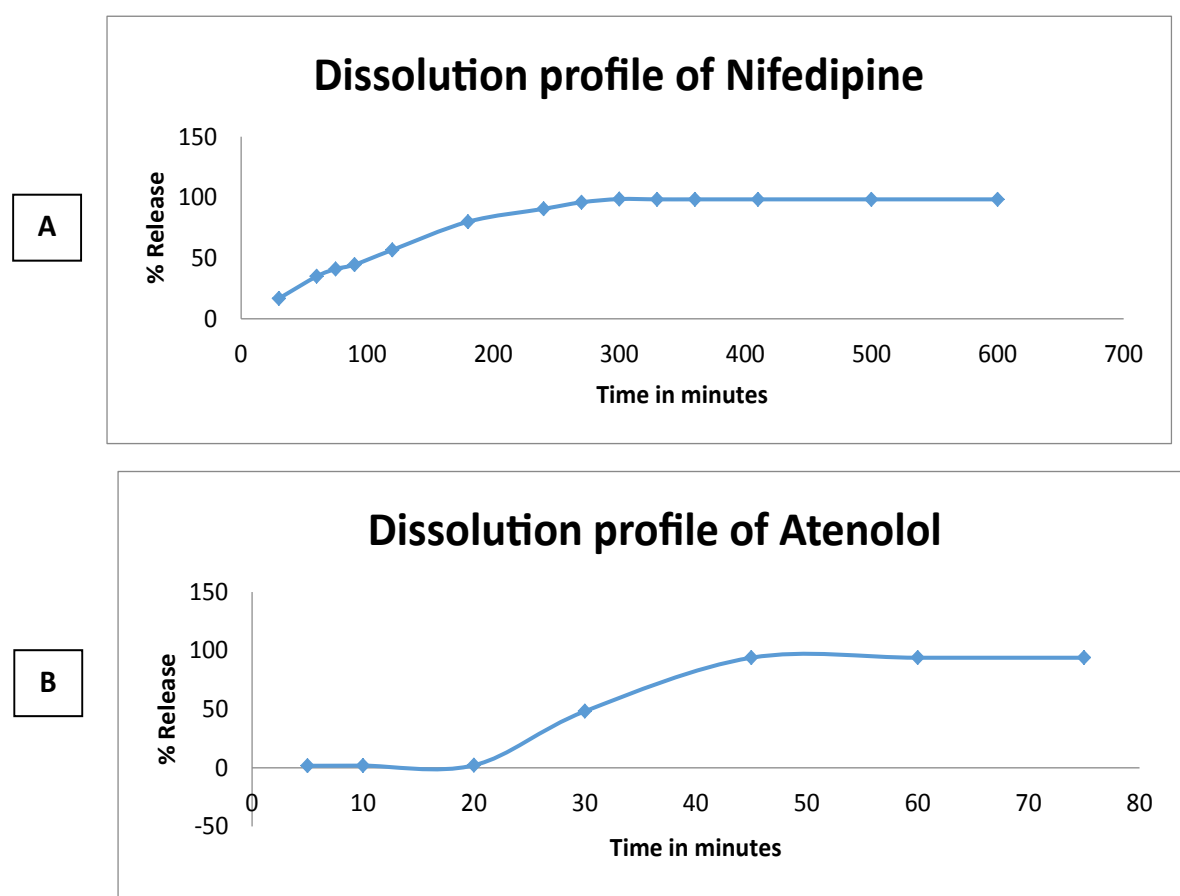

Figure 9: Dissolution of (A) nifedipine and (B) atenolol using USP apparatus method with $1 \%$ SLS.

and chromatographic methods were statistically compared to those of the reported HPLC method by Vidyadhara et al. [18] used for both nifedipine and atenolol analysis. It is conducted that; $95 \%$ confidence, there is no significant difference between them since the calculated $\mathrm{t}$ - and F-values are less than the theoretical values; as presented in (Table 9).

\section{Conclusion}

In this work simple, sensitive, accurate, precise, reproducible, repeatable, specific and robust chemometric and chromatographic methods were established for the determination of nifedipine and atenolol in bulk powder and pharmaceutical preparations. The results 
Citation: Abdallah I, Ibrahim A, Ibrahim N, Rizk M, Tawakkol S (2015) Simultaneous Determination of Atenolol and Nifedipine by Using Spectrophotometric Method with Multivariate Calibration and HPLC Method Implementing "Design of Experiment". Pharm Anal Acta 6: 384. doi:10.4172/21532435.1000384

Page 9 of 9

\begin{tabular}{|c|c|c|c|c|c|c|c|c|}
\hline \multirow{2}{*}{ Parameters } & \multicolumn{2}{|c|}{ PCR } & \multicolumn{2}{|c|}{ PLS } & \multicolumn{2}{|c|}{ HPLC } & \multicolumn{2}{|c|}{ Reported HPLC method } \\
\hline & NIF & ATN & NIF & ATN & NIF & ATN & NIF & ATN \\
\hline Mean & 100.60 & 100.75 & 100.50 & 100.78 & 100.40 & 99.74 & 100.75 & 100.43 \\
\hline SD & 0.96 & 0.42 & 0.85 & 1.07 & 0.36 & 0.81 & 0.42 & 0.51 \\
\hline $\mathbf{N}$ & 5 & 5 & 5 & 5 & 5 & 5 & 5 & 5 \\
\hline Variance & 0.92 & 0.18 & 0.72 & 1.14 & 0.12 & 0.65 & 0.18 & 0.26 \\
\hline $\begin{array}{l}\text { t-test } \\
(2.306)^{a}\end{array}$ & 0.33 & 0.52 & 0.59 & 0.65 & 1.39 & 1.58 & - & - \\
\hline $\begin{array}{l}\text { F-test } \\
(6.388)^{b}\end{array}$ & 5.11 & 4.58 & 4.04 & 4.38 & 1.32 & 2.54 & - & - \\
\hline
\end{tabular}

aThe values in parentheses are the corresponding tabulated values at $\mathrm{P}<0.05$.

${ }^{b} \mathrm{HPLC}$ method $\left(\mathrm{C}_{18}\right.$ Agilent ODS column, $(5 \mu \mathrm{m}, 250 \mathrm{~mm} \times 4.6 \mathrm{~mm}$, id. column), using methanol: acetonitrile: $0.025 \mathrm{M}$ sodium dihydrogen phosphate $60: 20: 20 \mathrm{v} / \mathrm{v} / \mathrm{v}$ and adjusted to $\mathrm{pH} 3$ with phosphoric acid, flow rate $1 \mathrm{~mL} / \mathrm{min}, 235 \mathrm{~nm}$ )

Table 9: Statistical comparison of the results obtained by the proposed spectrophotometric and RP-HPLC methods and with the reported HPLC method [18] for the analysis of nifedipine and atenolol in Tenolate® SR capsules.

obtained from both methods were compared to those of the reported HPLC method and a good coincidence was observed as there was no significant difference between both methods and the reported HPLC method. However, the chemometric method is less expensive and don't require sophisticated instrumentation nor any prior separation step. The multivariate methods are characterized by being fast, easy, and simple. While, the RP-HPLC was developed using the DOE concept which lead to a highly robust method of high specificity and good resolution. The proposed methods are quite sensitive for quantitative determination of nifedipine and atenolol in their pharmaceutical preparations and also used for their dissolution and release studies and hence used for routine analysis and quality control.

\section{References}

1. British Pharmacopoeia, Her Majesty's Stationary Office, London, UK, 2013., Br Pharmacopoeia, Her Majesty's Station. Off. London, UK, 2013. (2013).

2. N. M (2010) Drug treatment of elevated blood pressure. Aust Prescr 33: 108112

3. Freemantle N, Cleland J, Young P, Mason J (1999) $\beta$ Blockade after myocardia infarction: Systemic review and meta regression analysis. BMJ 318: 1730-1737.

4. K.B.R. Wise B M, Process Analytical Chemistry: Process Chemometrics, Blackie Academic \& Professional, Glasgow., (1995).

5. Gabrielsson J, Lindberg N (2002) Multivariate methods in pharmaceutical applications. Chemometrics 16: 141-160.

6. Deming SN, Morgan SL (1987) Experimental design: A chemometric approach, Elsevier.

7. Neto BDB, Bruns R, Scarminio I (2006) Statistical design-Chemometrics, Elsevier.

8. Plackett RL, Burman JP (1946) The Design of Optimum Multifactorial Experiments. Biometrika Trust 33: 305-325.

9. Sable KS, Ghadge NN, Hole MB, Gadhave MV (2012) Development of a UVspectrophotometric method for the simultaneous determination of nifedipine and atenolol in combined dosage form. Int J Inst Pharm Life Sci 2: 380-389.

10. Askal HF, Abdelmegeed OH, Ali SM, El-Hamd MA (2010) spectrophotometric and spectrofluorimetric determination of 1,4 dihydropyridine drugs using potassium permengnate and cerium IV ammonium sulphate. Bull Pharm Sci 33: 201-215.

11. Kasture AV, Madhuri R (2005) Simultaneous UV-Spectrophotometric methods for the estimation of Atenolol and Nifedipine in solid dosage forms. Ind J Pharm Sci 67: 752-754

12. Shelke OS, Sable KS, Neharkar VS, Mathdevru BV (2012) Development and validation of a UV spectrophotometric method for the simultaneous determination of nifedipine and atenolol in combined dosage form. Int. Res J Pharm 3: 360-364.

13. Ghadge NN, Shinde AG, Hole MB, Kadam SS, Gaikwad DD (2013) UV spectrophotometric method for simultaneous determination of atenolol and nifedipine in solid dosage forms. Inven Rapid Pharm Anal Qual Assur 13: 637638.

14. Patel HB, Patel B, Shraddha P (2013) Development and validation of second order derivative spectrophotometric method for simultaneous estimation of atenolol and nifedipine in combined dosage form. Int J Pharm Sci Res 4: 3884 3888.

15. Bing L, De-fu H, Fei L (2004) HPLC determination of atenolol and nifedipine in compound atenolol tablets. Chinese J Pharm Ana 5: 485-486.

16. Chang JH, Deng SH, Wang HS (2004) Determination of atenolol and nifedipine in atenolol compound tablets by HPLC. Chinese J Pharm 1: 35-39.

17. Qing HU, Zhang SU, Wang KE Shen JI (2010) Determination of seven antihypertensive chemical drugs added illegally into traditional Chinese medicine and health food by HPLC-DAD. Chinese J Pharma 1-8.

18. Vidyadhara S, Sasidharb RLC, Kumar BP, Ramarao NT, Sriharita N (2012) Method development and validation for simultaneous estimation of atenolo and nifedipine in pharmaceutical dosage forms by RP-HPLC. Orient $\mathrm{J}$ Chem 28: 1691-1696

19. Kaila HO, Ambasana MA, Shah AK (2013) Development and validation of a reversed - phase ultra - performance liquid chromatographic method fo the simultaneous determination of six drugs used for combined hypertension therapy. J AOAC 96: 295-300.

20. Text on Validation of Analytical Procedures Q2A, International Conference on Harmonisation of Technical Requirements for Registration of Pharmaceuticals for Human Use, London, UK; , (1994).

21. Ostwal PP, Salunkhe PS, Jain MS, Sumit PJ (2011) Development and evaluation for tablet-in capsule of nifedipine and atenolol. Int J Pharm Bio Sci 1: $468-473$.

22. United States Pharmacopeia and National Formulary (USP 30 - NF 25) Rockville, MD: United States Pharmacopeia Convention; 2007:, (2007) 1458 2753

23. http://wiki.eigenvector.com/index.php?title=Using Cross-Validation., (n.d.).

24. Haaland DM, Thomas EV (1988) Partial least-squares methods for spectral analyses. 1. Relation to other quantitative calibration methods and the extraction of qualitative information. Anal Chem 60: 1193-1202.

25. US Food and Drug Adminstration. Pharmaceutical cGMPs for the 21st century a risk-based approach. FDA, Rockville, MD, (2002). 